\title{
MAPEAMENTO DE UNIDADES DE PAISAGEM COMO ANÁLISE DA PLANÍCIE COSTEIRA: RESERVA EXTRATIVISTA MARINHA CAETÉ- TAPERAÇÚ/BRAGANÇA-PA
}

\author{
Thais Sousa $^{(\mathrm{a})}$, Erlen Assis $^{(\mathrm{b})}$, Bruna Pontes $^{(\mathrm{c})}$, Estevão Barbosa $^{(\mathrm{d})}$ \\ (a) Graduanda em Tecnologia em Geoprocessamento, Universidade Federal do Pará, thais.elaine.pereira@ gmail.com \\ (b) Graduanda em Tecnologia em Geoprocessamento, Universidade Federal do Pará, erlen.ssis@gmail.com \\ ${ }^{(c)}$ Graduanda em Tecnologia em Geoprocessamento, Universidade Federal do Pará, bruna_pontes09@ yahoo.com.br \\ (d)Professor Doutor na Faculdade de Tecnologia em Geoprocessamento, Universidade Federal do Pará, \\ estevaobarbos@yahoo.com.br
}

\section{Eixo: DINÂMICA E GESTÃO DE ZONAS COSTEIRAS}

\begin{abstract}
Resumo
O presente trabalho produziu como resultado um mapa de unidades de paisagem na Planície Costeira Bragantina por meio de geotecnologias, utilizando uma abordagem metodológica que inclui técnicas de geoprocessamento, revisão bibliográfica e pesquisa de campo, no qual se tencionou demonstrar a eficiência do SIG para a análise de geossistemas costeiros e a importância da delimitação de unidades de paisagem dentro de reservas extrativistas marinhas.
\end{abstract}

Palavras chave: unidades de paisagem, RESEX, geoprocessamento, planícies costeiras, manguezal.

\section{Introdução}

Ao se iniciar o debate metodológico sobre geossistemas, faz-se necessário conceituar a paisagem, que de acordo com Bertrand (2004) é uma determinada porção do espaço na qual processos dinâmicos e transitórios, resultantes de elementos físicos, biológicos e antrópicos, que se influenciam mutuamente, formam um conjunto único e indissociável, em constante mudança. No rol dos estudos ambientais, a análise geossistêmica serve para avaliar as ações dos homens sobre a natureza, os limites dos recursos naturais existentes, índices de vulnerabilidade ambiental, as dinâmicas econômico-espaciais, os quais geram bases para gestão e proteção das unidades de paisagem (ROSS, 1992).

Exemplo disso são as reservas extrativistas (RESEX), que, são segundo Contente (2013), áreas utilizadas por povos tradicionais cuja subsistência se baseia no extrativismo e, complementarmente, na agricultura de subsistência e na criação de animais de pequeno porte. As RESEX têm como objetivos básicos proteger os meios de vida e a cultura dessas populações, e assegurar a reprodução social e o uso sustentável dos recursos naturais da unidade (CONTENTE, 2013). 
A proposta final do artigo é confeccionar o mapa das unidades de paisagem existentes dentro da RESEX Marinha de Caeté-Taperaçú, através da consulta às bases cartográficas incluindo as variáveis indicadas por Bertrand (2004) para análise do geossistema como unidade de paisagem: o potencial ecológico e a exploração biológica, por meio de análise visual de imagens do satélite LANDSAT 8. Procurou-se demonstrar a eficiência do geoprocessamento como ferramenta para os estudos relativos aos geossistemas costeiros e a importância da delimitação das unidades de paisagem dentro de reservas extrativistas.

\section{2. Área de estudo}

A RESEX Marinha de Caeté-Taperaçú está localizada no Município de Bragança, Estado do Pará, distante $251 \mathrm{~km}$ da capital, Belém. O Município abrigava 122.881 habitantes em 2010, com uma área total de $2.091,930 \mathrm{~km}^{2}$. A RESEX tem uma área de 420,68 $\mathrm{km}^{2}$ correspondente a $20 \%$ do território municipal. A RESEX foi criada através do decreto S/N de 20/05/2005. Sendo margeada pelo oceano Atlântico, rios Taperaçú e Caeté, e vários canais de maré, compondo-se de um espaço rico em manguezais, ecossistema ideal para reprodução de peixes e frutos do mar, dos quais os habitantes do litoral bragantino tem como principal atividade econômica a extração e comércio desses recursos naturais (CONTENTE, 2013).

\section{Procedimentos metodológicos}

Para a confecção do Mapa de Unidades de paisagem da RESEX Caeté-Taperaçú, foi necessária uma reinterpretação da metodologia proposta a partir de Bertrand (2004), agrupando variáveis (mapa 1) de acordo com o potencial ecológico (litologia, solos e hidrografia) e a exploração biológica (vegetação e uso da terra e dos recursos naturais). Foram utilizados, como bases, os mapas de unidades morfológicas e ambientes sedimentares da Planície Costeira Bragantina, elaborados por Souza Filho (1996).

A partir disso, fez-se a vetorização manual das unidades de paisagem, através da intepretação visual da imagem de satélite Landsat-8, sensor OLI, órbita-ponto 222 061, obtida no 02 de junho de 2013, às 13h19, registrada na maré baixa, cedida pelo USGS na plataforma Earth Explorer. Para tal, foi usada uma composição RGB 654, fusionada com a banda 8 pan-cromática, obtendo assim uma resolução de $15 \mathrm{~m}$, com a finalidade de atingir uma melhor resolução espacial da área estudada. Configurou-se o projeto para o Datum para WGS, projeção UTM zona 23s. O recorte do raster foi feito pela camada vetorial fornecida pelo ICMBIO, de limite da RESEX, e limites municipais cedidos pelo IBGE Censo 2010. A partir disto, realizou-se a vetorização manual das feições, em observância às diferenças visuais possíveis de identificação na escala de trabalho (1:70.000). Todos estes procedimentos foram executados utilizando o 


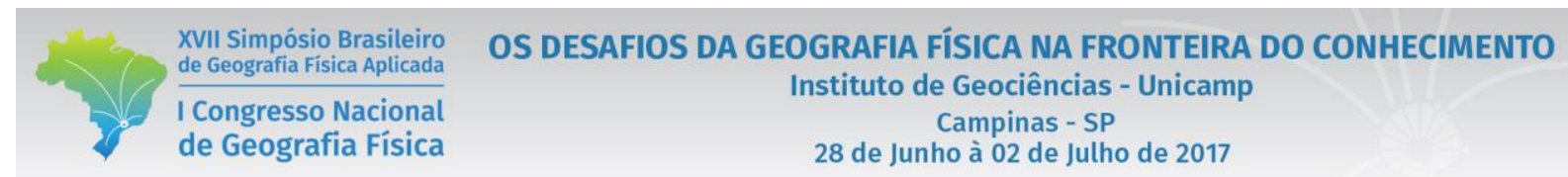

Software ArcGis, versão 10.1 (licenciado para a Universidade Federal do Pará - Campus Ananindeua), resultando no Mapa de Unidades de Paisagem da RESEX Marinha de Caeté-Taperaçú (Mapa 2).
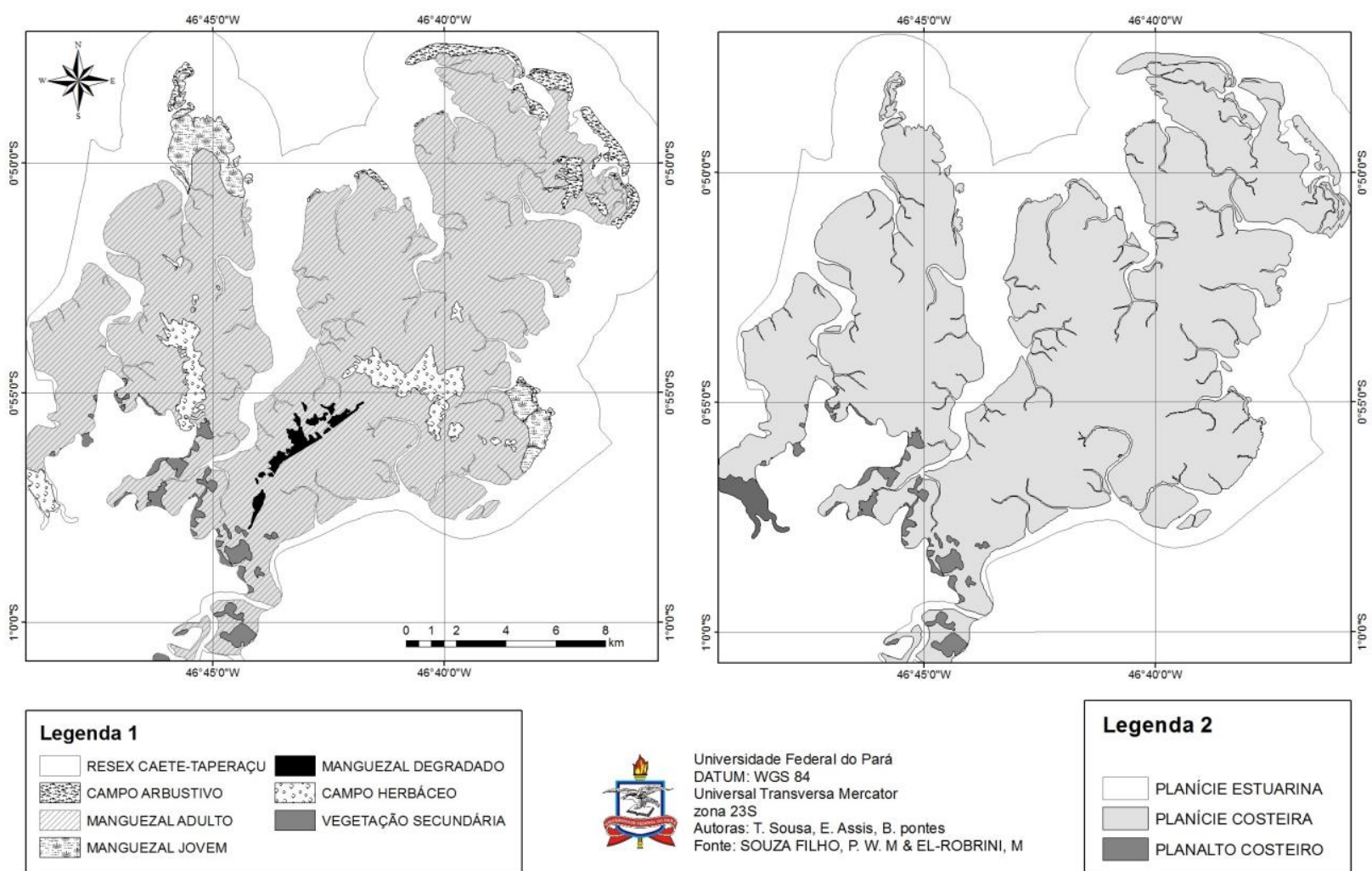

Legenda 2

PLANICIE ESTUARINA

PLANICIE COSTEIRA

PLANALTO COSTEIRO

Mapa 1- Vegetação e domínios geomorfológicos da RESEX

\section{Resultados e discussões}

Por meio das ferramentas de geoprocessamento, foi possível identificar oito unidades de paisagem na RESEX Marinha de Caeté-Taperaçú, e determinar aspectos como área, características biofísicas, uso e cobertura da terra. A RESEX apresenta uma área de $420 \mathrm{~km}^{2}$ cortados pela PA-458, que dá acesso à praia de Ajuruteua. As unidades de paisagem são: planícies arenosas, praias e dunas, chêniers, manguezal, manguezal degradado, pântano salino, terra firme e povoados.

De acordo com as análise de Souza Filho (1996), estas unidades de paisagem estão distribuídas em dois principais domínios sedimentares: a planície costeira, e o baixo planalto costeiro (mapa 1). 


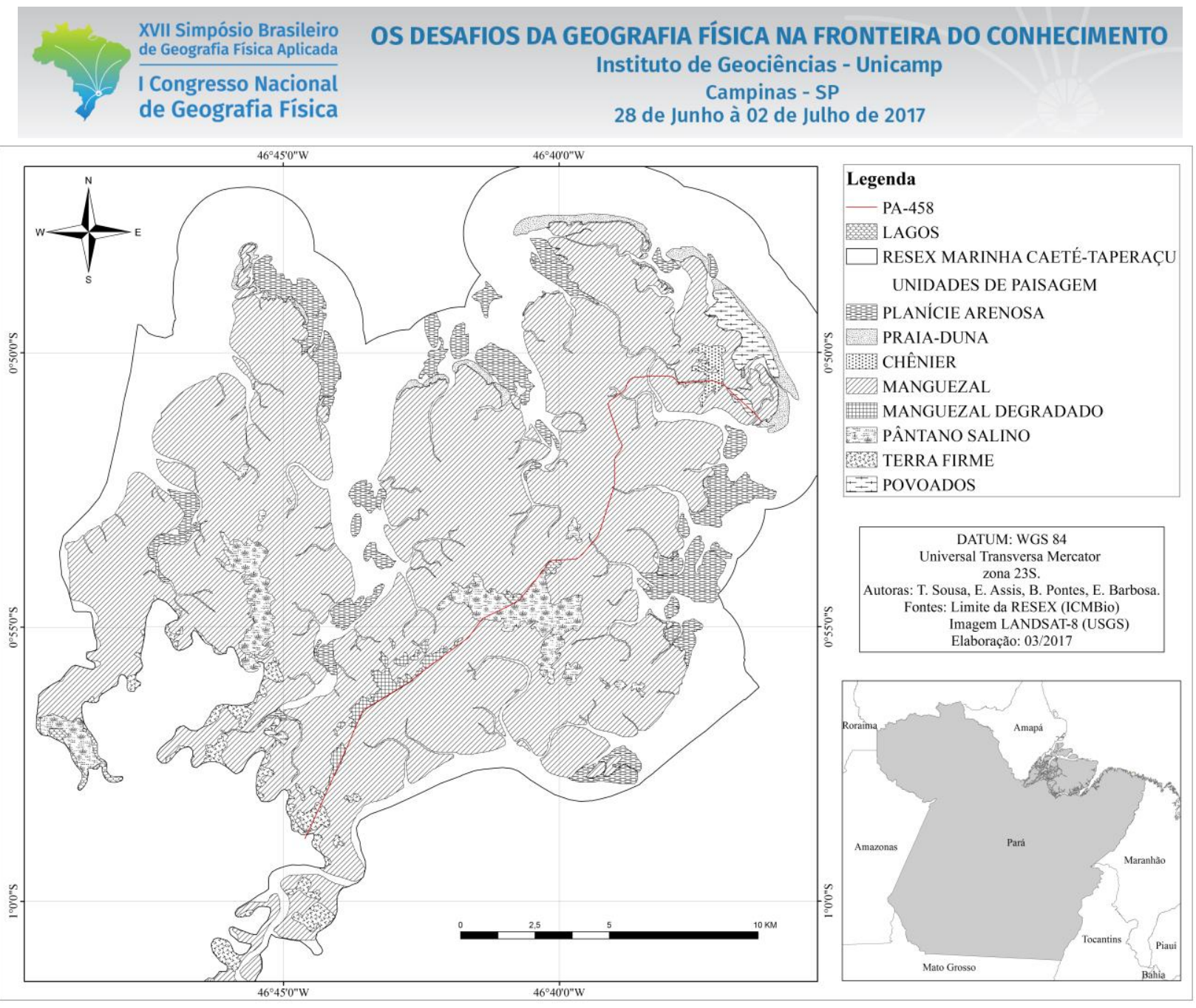

Mapa 2- Unidades de Paisagem da RESEX marinha Caeté-Taperaçú

Na planície costeira, as planícies arenosas, cobrindo uma área de $26,1 \mathrm{~km}^{2}$ (6\% da área total), são superfícies planas do leito estuarino, recortadas por canais de maré, os quais, no caso da RESEX CaetéTaperaçú sofrem influência do oceânico Atlântico. Na sequência destas planícies, a unidade de praias e dunas, com 6,6 km² (1,0\%), caracteriza-se por baixas elevações arenosas, estendidas desde a linha de sizígia. Nos trechos mais consolidados, existe uma vegetação arbustiva permanente. Os chêniers são paleocordões de praias e dunas que ocupam 1,6 $\mathrm{km}^{2}(0,3 \%)$, repousados sobre depósitos lamosos e apresentando uma vegetação arbustiva.

Os manguezais bragantinos cobrem a maior parte da área da RESEX, $239 \mathrm{~km}^{2}$ (56\%), sendo constituídos por extensas planícies costeiras lamosas, situadas entre os níveis de maré alta de sizígia e média maré, periodicamente inundáveis, de águas salobras. São vegetados pelas espécies de mangue. Parte destes manguezais se encontram degradados pela ação antrópica (abertura da estrada), o que deu origem a uma nova unidade de paisagem com $2,25 \mathrm{~km}^{2}(0,5 \%)$. Os pântanos salinos, na porção interna da planície costeira, possuem uma área de $12 \mathrm{~km}^{2}$ (2,9\%), sob influência do domínio de supramaré, encaixados em 
uma rede de drenagem colmatada, alimentada, principalmente, por sedimentos finos fluviais oriundos da planície de maré lamosa. Sua vegetação é herbácea. As unidades de terra firme são encontradas dispersas em meio à planície costeira, sendo parte do baixo planalto costeiro. A área delas é de $6,45 \%$ (1,0\%). São pontos de uma altitude mais elevada, em média de 20 a $30 \mathrm{~m}$, situando-se, portanto, acima do nível máximo de inundação pelas águas dos rios, dos estuários, e das chuvas, favorece a vegetação secundária. Por fim, foram identificadas três áreas na unidade de paisagem dos povoados, com 3,16 km² (0,7\%), ocupadas por comunidades rurais ou semi-urbanas nas quais os moradores praticam atividades de subsistência, sendo diretamente dependentes dos recursos naturais existentes na reserva extrativista.

\section{Considerações finais}

Assim, por intermédio da delimitação de unidades de paisagem foi possível verificar como o geoprocessamento pode auxiliar na discriminação de geossistemas costeiros, apoiando-se, também, na bibliografia e trabalhos de campo, presentes na RESEX marinha Caeté-Taperaçú, apontando como os processos antrópicos anteriores a criação da reserva impactaram o sistema costeiro, como no caso da área de manguezal degradado em decorrência a abertura da PA-458 que dá acesso ao núcleo semi-urbano de Ajuruteua. Além de apontar seu potencial de exploração extrativista, como no caso da unidade de mangue que possui vasta extensão rica em crustáceos e peixes. Por seu carácter complementar da análise de exploração biológica e potencial ecológico, a delimitação de unidades de paisagem na RESEX pôde oferecer um melhor entendimento da organização geossistemica da paisagem, servindo assim de subsídio para posteriores estudos de fragilidade e limites de pressão antrópica, contribuindo para o planejamento do meio físico, manejo e manutenção deste geossistema fluvial.

\section{BIBLIOGRAFIA}

BERTRAND, G. Paisagem e geografia física global. Esboço metodológico. R. RAEGA, Curitiba, n. 8, Editora UFPR, p. 141-152, 2004.

CONTENTE, A. C. P. Bragança: um breve olhar sobre a reserva extrativista caeté-taperaçú. Amazônia, Revista Antropologia, p.682-706, 2013.

ROSS, J. L. S. O registro cartográfico dos fatos geomórficos e a questão da taxonomia do relevo. Revista do Departamento de Geografia, n. 6, São Paulo,1992.

SOUZA FILHO, P. W. M \& EL-ROBRINI, M. Morfologia, processos de sedimentação e litofácies dos ambientes morfosedimentares de Planície Costeira Bragantina - Nordeste do Pará (Brasil). Geonomos, 4: 1-16, 1996. 


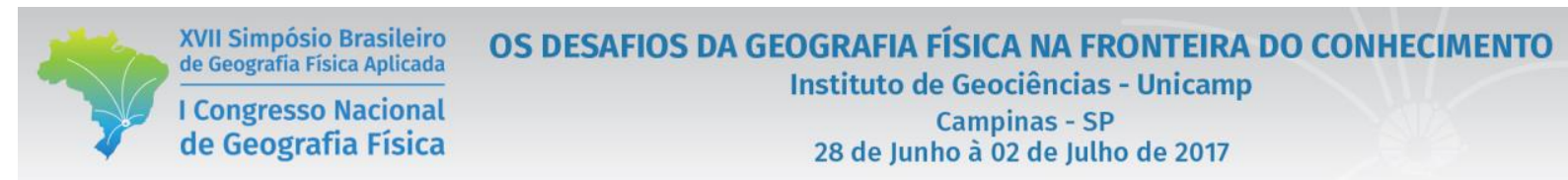

TEIXEIRA, E.; SOUZA FILHO, P. W. M Mapeamento de ambientes costeiros tropicais (Golfão Maranhense, Brasil) utilizando imagens de sensores remotos orbitais. Revista Brassileira de Geofísica. vol.27. São Paulo 2009. 